\title{
Updates in the Management of Alpha-1 Antitrypsin Deficiency Lung Disease
}

\author{
Khushboo Goel, ${ }^{1,2}$ Charlie Strange, ${ }^{3}$ Robert A Sandhaus, ${ }^{1}$ Irina Petrache ${ }^{1,2}$ and Karina A Serban ${ }^{1,2}$ \\ 1. Department of Medicine, Division of Pulmonary, Critical Care, and Sleep Medicine, National Jewish Health, Denver, CO, USA; 2. Department \\ of Medicine, Division of Pulmonary Sciences and Critical Care Medicine, University of Colorado, Aurora, CO, USA; 3. Division of Pulmonary, \\ Critical Care, Allergy and Sleep Medicine, Medical University of South Carolina, Charleston, SC, USA
}

A Ipha-1 antitrypsin deficiency, a genetic disorder caused by mutations within the SERPINA1 gene, increases the risk for early emphysema and chronic obstructive pulmonary disease in both never- and active-smokers. Short of a curative approach, alpha- 1 antitrypsin deficiency lung disease benefits from standard medical treatment with inhaled bronchodilators and corticosteroids, intravenous augmentation therapy with human alpha-1 antitrypsin purified from pooled plasma, and, in advanced stages, from lung transplantation. This review's learning objectives are to provide mechanistic and evidence-based data, as well as patient-related outcomes regarding the management of alpha-1 antitrypsin deficiency lung disease. Established and novel therapies for alpha-1 antitrypsin deficiency lung disease with published clinical efficacy and safety data are discussed.

\section{Keywords}

Alpha-1 antitrypsin deficiency, emphysema, alpha-1 augmentation therapy, gene therapy, hyaluronic acid, neutrophil elastase inhibitor, corrector molecule

Disclosures: Khushboo Goel has no financial or non-financial relationships or activities to declare in relation to this article; she received grant support from NHLBI (F32HL158086). Charlie Strange has received grants to the Medical University of South Carolina from Adverum, Alpha-1 Foundation, Arrowhead, CSL Behring, Grifols, MatRx, Takeda and Vertex; has received consulting fees from AstraZeneca and Dicerna; has received speaker's honoraria from the American Thoracic Society; serves on the Documents Committee for the American Thoracic Society; serves on the Medical and Scientific Advisory Board for Alpha-1 Foundation; and serves as a medical director for AlphaNet. Robert A Sandhaus has served on advisory committees for Grifols and CSL Behring (travel and honorarium to AlphaNet), Takeda (honorarium paid to AlphaNet), AstraZeneca, Dicerna (honorarium paid to AlphaNet), Arrowhead (honorarium and trave paid to ALphaNet), InhibRX, Korro-Bio; serves as medical director for AlphaNet; serves as clinical director for Alpha-1 Foundation (no payment); serves as medical director for AlphaNet Canada; serves as board member for Global Implementation Solutions; serves as medical advisory council for Osteogenesis Imperfecta Foundation; and serves as board member for Disease Management, Inc. Irina Petrache has received grant support to institution from NIH/NHLBl; serves as Wollowick Chair in COPD Research for National Jewish Health; has received consulting fees from Ceramedix, Allinaire and AstraZeneca; has received travel fees from the American Thoracic Society; and has served on committees for the American Thoracic Society. Karina A Serban has received grant support to institution from Alpha-1 Foundation (K08 HL141770-01A1); has served in a leadership role or on committees for Alpha-1 Foundation Grant Advisory Committee, Alpha-1 Foundation Medical Advisory and Scientific Committee, ATS - RCMB Program Committee, ATS - RCMB Website Committee and National Jewish Health IBC committee.

Acknowledgements: We acknowledge Elizabeth Kellermeyer, Biomedical Research Librarian, Library and Knowledge Services at National Jewish Health for her assistance with online literature search and access to restricted publications.

Review process: Double-blind peer review.

Compliance with ethics: This study involves a review of the literature and did not involve any studies with human or animal subjects performed by any of the authors.

Data availability: Data sharing is not applicable to this article as no

datasets were generated or analysed during the current study.

Authorship: The named authors meet the International Committee of Medical Journal Editors (ICMJE) criteria for authorship of this manuscript, take responsibility for the integrity of the work as a whole, and have given final approval for the version to be published.

Access: This article is freely accessible at touchRESPIRATORY.com.

(C) Touch Medical Media 2021

Received: 13 July 2021 Accepted: 8 September 2021

Published online: 23 December 2021

Citation: touchREVIEWS in Respiratory \& Pulmonary Diseases. 2021;6(1):26-30

Corresponding author: Karina Serban, Department of Medicine, Division of Pulmonary, Critical Care, and Sleep Medicine, National Jewish Health, 1400 Jackson St, K825, Denver, CO 80206, USA. E: serbank@njhealth.org
Alpha-1 antitrypsin (AAT) deficiency (AATD) is the second most common genetic disease to cause clinically significant lung disease, surpassed only by cystic fibrosis. ${ }^{1}$ AAT is a serine protease inhibitor primarily produced in hepatocytes, with a normal plasma level of 20-53 $\mu \mathrm{M}$ or 90-200 mg/dL and a half-life of 3-5 days. ${ }^{2}$ AAT is transported via the systemic circulation to the lung, where it is actively taken up by the lung endothelial cells and transferred to the epithelial cells and alveolar space. ${ }^{3}$ AATD results from inherited mutations within the SERPINA1 gene, with $\mathrm{Pi}{ }^{*} \mathrm{ZZ}$ being the most common genotype associated with clinically significant disease, leading to low serum levels of the AAT antiprotease and protease/antiprotease imbalance. Qualitative defects of AAT result from acquired post-translational modifications, such as polymerization, oxidation and nitrosylation, and are associated with decreased and inefficient neutrophil elastase inhibition despite low or normal serum levels of the AAT protein. ${ }^{4,5}$

\section{Alpha-1 antitrypsin lung disease}

Ever since genetic testing has been recommended for all individuals with chronic obstructive pulmonary disease (COPD), ${ }^{6}$ AATD has been identified as the most common genetic risk factor for early emphysema in both never- and active-smokers. ${ }^{7}$ In fact, $3-10 \%$ of patients with emphysema-predominant COPD have abnormal AAT variants. ${ }^{18,9}$ The classic presentation of AATD is severe, panacinar, bilateral, lower lobe emphysema, airflow limitation and decreased diffusion capacity for carbon monoxide (DLCO). ${ }^{1}$

An imbalance between proteases, such as neutrophil elastase, and anti-proteases, including AAT, with subsequent degradation of elastic fibres, has been the main pathobiological mechanism implicated in the development of AATD-related emphysema. ${ }^{10}$ Degradation of elastin produces crosslinked elastin peptides containing desmosine and isodesmosine, which are excreted in the urine; levels of these peptides correlate with emphysema progression and treatment response..$^{11,12}$ Uninhibited neutrophil elastase present in AATD results in increased fibrinogen degradation products in the serum, which can also be used as a biomarker for treatment response. ${ }^{12-13}$

Traditional markers of COPD severity, such as lung function decline and computed tomography (CT) measurements of lung density, require 
a certain level of lung injury to effectively diagnose and monitor the disease. Therefore, it has been suggested that plasma markers of elastin degradation (e.g. matrix metalloprotease-3 and -9), inflammation (e.g. C-reactive protein, ceruloplasmin) and repair (e.g. leptin, gelsolin, insulin-like growth factor binding proteins) may become alternatives to assess the severity of emphysema at baseline, and its progression. 11,14,15 Inflammatory mediators in the bronchoalveolar lavage such as interleukins, cytokines (including tumour necrosis factor- $\alpha$ ), eotaxin and growth factors, have been used to monitor treatment response. ${ }^{16,17}$ None of these biologic signals has, to date, been recommended by guidelines or regulatory authorities for clinical disease management.

While the association between AATD and early emphysema is well described in patients with the Pi*ZZ genotype, AATD's association with airway diseases manifesting as bronchiolitis, bronchitis and bronchiectasis is less well characterized. ${ }^{18}$ Of these, only severe bronchiectasis is considered a 'clinically relevant' AATD manifestation, but only when involving more than one lobe and associated with symptoms of cough and sputum production. ${ }^{19}$ However, all airway structural changes, even when minimally symptomatic, may impact clinical outcomes in AATD lung disease, including health status ${ }^{17}$ and airflow limitation. ${ }^{20}$

\section{Established therapies}

Current data suggest that individuals with AATD diagnosed with COPD benefit as much from medical treatment with bronchodilators, inhaled corticosteroids, pulmonary rehabilitation, supplemental oxygen therapy, low-dose azithromycin, roflumilast and immunizations as those with cigarette smoke-induced COPD. ${ }^{21}$ Patients with AATD are considered poor candidates for lung volume reduction surgery (LVRS) due to homogeneous, predominantly lower lobe emphysema, which contrasts with the predominantly upper lobe localization of emphysema in patients with COPD who typically benefit from LVRS. ${ }^{22}$ Survival post-double-lung transplantation for end-stage lung disease is similar in patients with AATD and those with cigarette smoke-induced COPD, rendering lung transplantation a viable option..$^{23}$

The concept of maintaining a 'protective threshold' of AAT serum levels above $11 \mu \mathrm{M}(50 \mathrm{mg} / \mathrm{dL}),{ }^{24}$ although somewhat controversial, has been the cornerstone of developing AAT replacement or restoration therapies for AATD. Augmentation therapy, which involves weekly intravenous infusion of purified human AAT aiming to achieve levels $\geq 11 \mu \mathrm{M}$, is the most widespread therapeutic approach for AATD. ${ }^{25}$ Augmentation therapy with $120 \mathrm{mg} / \mathrm{kg}$ every 2 weeks has also been studied as an alternative to weekly dosing, but serum AAT levels were shown to decrease below $11 \mu \mathrm{M} 1-2$ days prior to the next dose. ${ }^{26}$ As such, weekly augmentation therapy with AAT $60 \mathrm{mg} / \mathrm{kg}$ has become the standard of care for patients severely deficient in AAT, especially those with forced expiratory volume in one second (FEV1) $\leq 65 \%$ predicted, in whom we have the best evidence for significant clinical benefit. ${ }^{27}$

Tortorici et al., who found that clinical efficacy did not plateau as AAT exposure was increased, suggested that there may be a role for higher AAT doses. ${ }^{28}$ The SPARK trial (Safety and Pharmacokinetics of Alpha-1 Proteinase Inhibitor in Subjects with Alpha-1 Antitrypsin Deficiency; ClinicalTrials identifier: NCT01213043) in 2013 found that double-dose 120 $\mathrm{mg} / \mathrm{kg} /$ week achieved a higher mean steady state serum concentration of $27.7 \mu \mathrm{M}$ (versus $17.3 \mu \mathrm{M}$ in the $60 \mathrm{mg} / \mathrm{kg} /$ week group) with a similar safety profile..$^{29} \mathrm{~A}$ follow-up pilot study with eight patients with AATD was conducted in 2019, which found that double-dose therapy for 4 weeks significantly reduced serine protease activity in bronchoalveolar lavage fluid (BALF) and plasma, and reduced markers of elastin degradation (desmosine, isodesmosine) in BALF.16

Because the kinetics of augmentation therapy are well known, measurement of trough serum levels after $60 \mathrm{mg} / \mathrm{kg}$ weekly or 120 $\mathrm{mg} / \mathrm{kg} /$ week doses are not recommended. The SPARTA trial (Efficacy and Safety of Alpha1-Proteinase Inhibitor (Human), Modified Process (Alpha-1 MP) in Subjects With Pulmonary Emphysema Due to Alpha1 Antitrypsin Deficiency (AATD); ClinicalTrials identifier: NCT01983241), an ongoing phase III clinical trial, will evaluate whether the progression of lung tissue loss is mitigated in patients with AATD lung disease receiving augmentation therapy at $120 \mathrm{mg} / \mathrm{kg} /$ week compared with $60 \mathrm{mg} / \mathrm{kg} /$ week. $^{30}$ If this higher dose regimen shows additional benefit, it will not only change therapeutic approaches for patients severely deficient in AAT, but will also prompt consideration of augmentation therapy for intermediately deficient (Pi*MZ) individuals with lung disease, with circulating AAT levels above $11 \mu \mathrm{M}$. Of note, current guidelines advise against using augmentation therapy in patients with the $\mathrm{P}{ }^{*} \mathrm{MZ}$ genotype, since most will not develop significant lung disease unless being exposed to cigarette smoking. ${ }^{31}$

In addition to measuring the rate of FEV1 decline, lung density quantified by $\mathrm{CT}$, a more sensitive test, performs well in clinical trials to longitudinally estimate the efficacy of augmentation therapy in patients with AATD. ${ }^{32}$ Dirksen et al., 1999, ${ }^{33}$ Dirksen et al., 2009,,34 and Chapman et al., 2015 (RAPID study; Zemaira in Subjects with Emphysema Due to Alpha1Proteinase Inhibitor Deficiency; ClinicalTrials identifier: NCT00261833), ${ }^{35}$ are the three seminal randomized controlled trials that chose decline in lung density measured by CT as a primary or secondary outcome to study the efficacy of augmentation therapy. ${ }^{35}$ Similarly, a 2-year openlabel extension trial (RAPID-OLE; Extension Study of Zemaira $\AA$ i.v. Administration in Subjects With Emphysema Due to Alpha1-Proteinase Inhibitor Deficiency; ClinicalTrials identifier: NCT00670007) showed that, compared with 2 years of placebo, augmentation therapy slowed the rate of lung density loss. ${ }^{36}$ Given the irreversible nature of the loss of lung parenchyma (that comprises lung density), early treatment recommendations were reinforced..$^{36} \mathrm{~A}$ post hoc analysis of the RAPID and RAPID-OLE trials compared the rate of lung density loss in augmentation therapy versus placebo, and projected a gain of 5.6 life-years, defined as the time to terminal respiratory failure, in the treatment group. ${ }^{35-37}$ Also, a retrospective analysis of the National Heart, Lung, and Blood Institute AATD Registry found that augmentation therapy was associated with improved survival in individuals receiving augmentation therapy at all 10\% increments of FEV1 from 10\% to 60\%, further supporting early initiation of augmentation therapy. ${ }^{38}$ Interestingly, few studies have studied the role of augmentation therapy in AATD lung transplant recipients; however, post-transplantation augmentation therapy is still recommended by several experts. ${ }^{39}$

Multiple commercial preparations of AAT from pooled human plasma have been developed over the years, which have similar efficacy and safety profiles, but may differ in the convenience of infusion duration and setup. For example, formulations with a higher purity profile allow for a more concentrated product and thus a lower infusion volume and time. ${ }^{40}$ Liquid formulations (compared with the standard lyophilized formulation) make administration more convenient by eliminating the need for product reconstitution, reducing storage space needed given the lack of diluent packaging, and requiring less volume for infusion. .11,42 $^{2}$ 
Despite the potential survival benefits of augmentation therapy, indefinite weekly infusions come with significant financial, emotional and social burden on patients with AATD and their families. In fact, the estimated annual medical cost among US patients with AATD on augmentation therapy is $\$ 127,537$ compared with $\$ 15,874$ for those with AATD receiving usual COPD care without augmentation therapy, with $75.3 \%$ of the cost difference attributable to augmentation therapy. ${ }^{43}$ In a recent review, Chorostowska-Wynimko et al. advocated for patientcentric initiatives to improve the convenience of AAT therapy through extended-interval dosing, such as double-dose every other week during vacations, or self-infusion at home.44 In addition, Campos et al. showed that a health management programme, which includes a clinical coordinator and infusion and insurance specialists, reduced the rate of severe exacerbation episodes by $36.1 \%$ and adjusted total all-cause and respiratory-related costs by $11.4 \%$ and $10.6 \%$, respectively. ${ }^{45}$ The COVID-19 pandemic has made it difficult for many patients to access the hospital for augmentation therapy and, unfortunately, home-based therapy is an alternative offered in very few countries. Annunziata et al. showed that 16 patients receiving home-based intravenous augmentation therapy had improved quality of life compared to patients without home-based therapy. ${ }^{46}$

The highly specialized care required for AAT infusions, the unproven efficacy in heterozygous patients with AATD and COPD, the inability to fully recover the lung function lost at the time of treatment initiation and the limited availability of human plasma for AAT purification has put pressure on the field to develop personalized therapies that are easier to administer in both early and advanced AATD lung disease and, if possible, target a specific SERPINA1 mutation.

\section{Novel therapies}

A new attempt at redefining therapy in AATD was to extend the half-life of human AAT with an engineered, recombinant, human AAT-FC (fragment crystallizable region) fusion protein (INBRX-101; Inhibrx, La Jolla, CA, USA). When administered at $120 \mathrm{mg} / \mathrm{kg}$ every 3 weeks, it maintains the AAT serum level in the expected range, while its maximal anti-elastase activity is preserved. Its efficacy is currently unknown; an open-label phase I study was started in July 2019 and will enroll patients until December 2021 (ClinicalTrials.gov identifier NCT03815396). ${ }^{47}$

To address the occasional shortage of pooled human plasma for AAT purification, the field has turned towards finding alternative sources of AAT, from recombinant AAT product from plants to reprogramming progenitors/stem cells to secrete exogenous human AAT when delivered in the lung. ${ }^{48}$ In the era of regenerative medicine, we and others have shown that the adipose-derived mesenchymal stem cell (MSC)secretome contains AAT with high anti-elastase in vitro activity and other

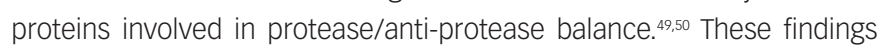
position allogenic MSC as a novel therapeutic option for AATD patients. Although augmentation therapy has traditionally relied on delivering AAT intravenously (since AAT produced in hepatocytes reaches the lungs through systemic circulation), inhaled AAT achieves much higher local levels of AAT in the airway epithelial lining. ${ }^{51,52}$ Inhaled AAT may be less expensive and more convenient for patients than intravenous formulations. ${ }^{53,54}$ However, the enthusiasm for its use was tempered by the findings of Stolk et al.; when 168 patients were randomized to receive twice-daily inhalations of $80 \mathrm{mg}$ AAT solution or placebo for 50 weeks, the average yearly exacerbation rate in the inhaled AAT treatment group was similar to that of the placebo group, with more patients receiving inhaled AAT reporting treatment-related adverse events, prompting modifications of the nebulizer used. ${ }^{55}$ Other trials of inhaled
AAT are ongoing (ClinicalTrials identifiers: NCT01217671, NCT02001688, NCT00161707, NCT01983241) ${ }^{56-59}$ that will report whether inhaled AAT is safe, well tolerated and clinically effective. ${ }^{60}$

Other approaches to ameliorate the damage to lung tissue caused by the protease/anti-protease imbalance in AATD are emerging. Hyaluronan or hyaluronic acid (HA), a long-chain polysaccharide that protects against elastin fibre breakdown, is a promising new therapy. ${ }^{61}$ Patients with AATD and COPD were found to have significantly decreased HA levels in lung tissue (13.5 ng/mg wet lung; $\mathrm{n=9}$ ) compared with controls $(21.7 \mathrm{ng} / \mathrm{mg}$ wet lung; $n=5$ ), with a direct correlation between HA levels and FEV1, DLCO and serum AAT levels. ${ }^{62}$ Cantor et al. conducted a 2-week phase Ila safety trial in 11 patients with COPD (eight receiving HA 0.01\% aerosol twice a day for 14 days, and three receiving placebo) and did not observe significant adverse events. ${ }^{63}$ They followed this study with a phase II, 28day randomized trial of twice-daily HA $0.03 \%$ in patients with AATD and COPD; the results, published in 2021, show a progressive reduction in free urine desmosine and isodesmosine in the HA group starting at day 14 , which was maintained up to day $35 .{ }^{64}$

Following promising results in non-cystic fibrosis bronchiectasis, the reversible oral inhibitor of neutrophil elastase, alvelestat (Mereo BioPharma, London, UK), has made important strides as a novel therapy for AATD lung disease..$^{65}$ It is currently under investigation in two phase II, placebo-controlled clinical trials, ASTRAEUS (A 12week Study Treating Participants who have Alpha1-AntitrypsinRelated COPD with Alvelestat (MPH966) or Placebo; ClinicalTrials identifier: NCT03636347) ${ }^{66}$ and ATALANTa (Alvelestat (MPH966) for the Treatment of Alpha-1 Antitrypsin Deficiency; ClinicalTrials identifier: NCT03679598). ${ }^{67}$ Alvelestat is not the only oral protease inhibitor currently in clinical trials. PHP-303 (pH Pharma, Seongnam, South Korea) is a novel molecule being studied in phase II clinical trials primarily targeting AATD liver disease, with secondary endpoints including lung outcomes pertinent to AATD lung disease.

Another therapeutic approach is to correct and promote the proper folding of the mutant Z-AAT protein. VX-864 (Vertex Pharmaceuticals, Boston, MA, USA), an oral small molecule corrector, was studied in a phase II proof-of-concept study in patients with the Pi`ZZ genotype (ClinicalTrials identifier: NCT04474197), ${ }^{68}$ where it led to consistent increases in mean functional AAT levels of 2.2-2.3 $\mu \mathrm{M}$ from baseline without significant adverse events. ${ }^{69}$ However, the magnitude of VX-864's effect as studied may not translate into substantial lung protective effects, as AAT plasma levels remained well below the accepted threshold for efficacious inhibition of neutrophil elastase. ${ }^{69}$

From the therapies targeting the liver, ARO-AAT (Arrowhead Pharmaceuticals, Pasadena, CA, USA) is a hepatocyte-targeted inhibitory ribonucleic acid (RNAi) designed to inhibit the expression of the mutated Z-allele of alpha-1 antitrypsin (Z-AAT) messenger RNA (mRNA) and subsequently reduce Z-AAT protein synthesis. Preliminary data in patients with the $\mathrm{P}{ }^{*} \mathrm{ZZ}$ genotype showed significant improvement in liver parameters at week 24 and no detrimental or beneficial effect on AATD lung disease. ${ }^{70}$

Although the lung disease in patients with the Pi*ZZ or $\mathrm{Pi}{ }^{*} \mathrm{SZ}$ genotypes progresses independent of their liver disease status, those with endstage liver disease who are candidates for liver transplantation because of the severity of their liver dysfunction may also have a slower rate of lung function decline post-liver transplantation. ${ }^{11}$ This may be linked to normal AAT levels detected in patients soon after transplantation. ${ }^{72}$ Due 
Figure 1: Schematic of established and novel therapies available for alpha-1 lung disease

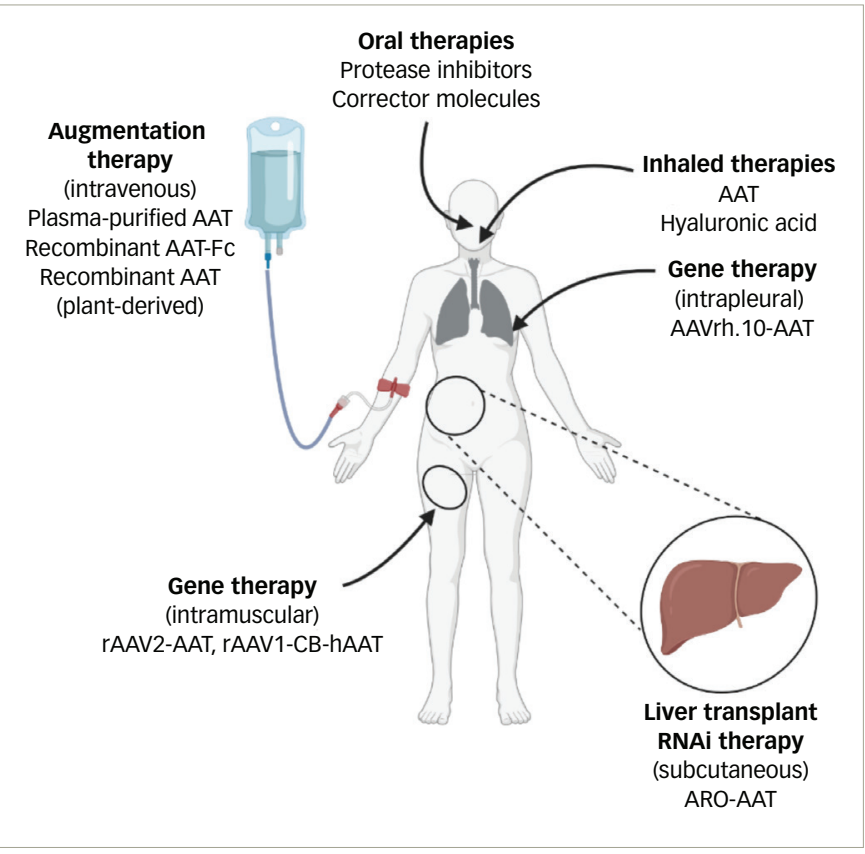

Besides established intravenous augmentation therapy with plasma-purified AAT, other sources of AAT have been identified for intravenous administration: engineered recombinant human AAT-FC fusion protein and plant-derived AAT. Novel therapies focus on a convenient route of administration, e.g. oral and inhaled. Novel therapies also address different aspects of AATD pathogenesis: gene therapy aiming to decrease $Z$-AAT liver production and secretion, and to increase M-AAT secretion from the skeletal muscle or pleural space: corrector molecules aiming to promote proper folding of the Z-AAT protein; and inhaled hyaluronic acid aiming to protect against lung elastin fibres breakdown. Image was created in Biorender.com.

$A A T=$ alpha-1 antitrypsin; $A A T-F C=$ alpha- 1 antitrypsin fused with FC region of immunoglobulin; rAAV = recombinant adeno-associated virus vector; $R N A i=$ inhibitory ribonucleic acid.

to its risks, liver transplantation is not being considered for patients with AATD lung disease in the absence of severe liver dysfunction. .1,72 $^{1,7}$

Gene therapy offers the possibility for a one-time administration to provide therapeutic levels of AAT to protect against lung injury. Lungs are a promising organ for gene therapy, since the vector can be delivered directly via nebulization, pleural administration or intramuscular administration; however, challenges include the barrier posed by the mucus lining of the airway epithelium, which can trap vectors, and the relatively rapid renewal of the epithelial cells requiring repeated therapeutic administration. ${ }^{73}$ Adeno-associated viral (AAV) vectors, considered safer than other types of vectors because they do not integrate into the genome, were first used in AATD gene therapy. ${ }^{73}$ In a phase I clinical trial, recombinant AAV serotype 2 vector expressing AAT (rAAV2-AAT) was administered via intramuscular injection in 12 patients with AATD. The therapy yielded low levels of wild-type AAT, with the emergence of anti-rAAV2 antibodies. ${ }^{74}$ Interim results of a phase II trial using rAAV1-CB-hAAT intramuscular injection in nine patients with AATD indicated that the serum AAT levels were dose dependent, peaked at 30 days, but then decreased to 3-5\% off the target concentration for at least 90 days after a single administration. ${ }^{75}$

One current focus of gene therapy revolves around intrapleural administration of vectors, which, in mice, generated higher lung and serum AAT levels than intramuscular administration. ${ }^{76}$ Following the emergence of AAV rhesus macaque-derived serotype 10 (AAVrh.10-AAT) as the most efficient vector,"7 a phase I and II clinical trial assessed two different doses of intrapleural AAVrh.10-AAT (ADVANCE; Safety Dose Finding Study of ADVM-043 Gene Therapy to Treat Alpha-1 Antitrypsin (A1AT) Deficiency; ClinicalTrials identifier NCT02168686). ${ }^{78-80}$ However, an abstract published shortly after the end of the trial in 2018 showed that this approach did not lead to significant elevations in serum AAT. ${ }^{81}$

\section{Discussion}

Current AAT augmentation modalities for AATD lung disease offer significant advantages over regular COPD care, primarily by preserving lung function and CT lung density, especially in patients with the Pi*ZZ genotype and emphysema. Although it is challenging to study mortality benefits in this rare disease, post hoc and retrospective analyses of trials and registries have suggested an association between augmentation therapy and improved survival. ${ }^{82.83}$ Aside from the drawbacks of cost and the inconvenience of intravenous administration, the concept of augmenting AAT levels in deficient individuals could advance with novel sources of recombinant AAT either from plant or progenitor/stem cell sources. The real excitement comes from the progress being made with therapies targeting SERPINA1/AAT transcriptional and translational messaging, where gene therapy, RNAi, corrector molecules and novel oral protease inhibitors could alter AATD treatment in the next 3-5 years (Figure 1). Moreover, the new molecules will target AATD lung disease in a more personalized manner, which may addresS SERPINA1 mutations other than the Glu342Lys mutation (Z allele) and clinical phenotypes of AATD besides classical lower lobe emphysema.
1. Silverman EK, Sandhaus RA. Clinical practice. Alpha1-antitrypsin deficiency. N Engl J Med. 2009:360:2749-57.

2. Strnad P, McElvaney NG, Lomas DA. Alpha1-antitrypsin deficiency. N Engl J Med. 2020;382:1443-55.

3. Lockett $A D$, Brown MB, Santos-Falcon N, et al. Active trafficking of alpha 1 antitrypsin across the lung endothelium. PLOS One. 2014;9:e93979.

4. Carrell RW, Lomas DA. Alpha1-antitrypsin deficiency--a mode for conformational diseases. N Eng/ J Med. 2002;346:45-53.

Serban KA, Petrache I. Alpha-1 antitrypsin and lung cell apoptosis. Ann Am Thorac Soc. 2016;13 Suppl.2:S146-9.

American Thoracic Society, European Respiratory Society. American Thoracic Society/European Respiratory Society Statement: standards for the diagnosis and management of individuals with alpha-1 antitrypsin deficiency. Am J Respir Crit Care Med. 2003:168:818-900.

7. Silverman EK, Province MA, Campbell EJ, et al. Family study of alpha 1-antitrypsin deficiency: effects of cigarette study of alpha 1-antitrypsin deficiency: effects of cigare
smoking, measured genotype, and their interaction on smoking, measured genotype, and their interaction on
pulmonary function and biochemical traits. Genet Epidemio. pulmonary function

8. Lieberman J, Winter B, Sastre A. Alpha 1-antitrypsin Pi-types in 965 COPD patients. Chest. 1986;89:370-3.

9. da Costa $\mathrm{CH}$, Noronha Filho AJ, Marques E Silva RMF, et al. Alpha 1-antitrypsin deficiency in patients with chronic obstructive pulmonary disease patients: is systematic screening necessary? BMC Res Notes. 2019:12:10

10. Agné A, Richter K, Padberg W, et al. Commercial alpha1antitrypsin preparations markedly differ in their potential to inhibit the ATP-induced release of monocytic interleukin-1beta.
Pulm Pharmacol Ther 2021:68:102020.

11. Ferrarotti I, Corsico AG, Stolk J, et al. Advances in identifying urine/serum biomarkers in alpha-1 antitrypsin deficiency for more personalized future treatment strategies. COPD. 2017; 14:56-65

12. Ma S, Lin YY, Cantor JO, et al. The effect of alpha-1 proteinase inhibitor on biomarkers of elastin degradation in alpha-1 antitrypsin deficiency: an analysis of the RAPID/RAPID extension trials. Chronic Obstr Pulm Dis. 2016;4:34-44.

13. Stolk J, Nieuwenhuizen W, Stoller JK, Aboussouan L. High dose intravenous AAT and plasma neutrophil derived fibrinogen fragments. Thorax. 2005;60:84.

14. Omachi TA, Eisner MD, Rames A, et al. Matrix metalloproteinase-9 predicts pulmonary status declines in alpha1-antitrypsin deficiency. Respir Res. 2011;12:35.

15. Beiko T, Janech MG, Alekseyenko AV, et al. Serum proteins associated with emphysema progression in severe alpha-1 associated with emphysema progression in severe alpha-1

16. Campos MA, Geraghty $\mathrm{P}$, Holt $\mathrm{G}$, et al. The biological effects of Campos MA, Geraghty P, Holt G, et al. The biological effects of
double-dose alpha-1 antitrypsin augmentation therapy. A pilot double-dose alpha-1 antitrypsin augmentation therapy. A p
clinical trial. Am J Respir Crit Care Med. 2019;200:318-26.

7. Schmid ST, Joepke J, Dresel M, et al. The effects of weekly augmentation therapy in patients with PizZ alpha1-antitrypsin deficiency. Int I Chron Obstruct Pulmon Dis. 2012;7:687-96.

18. Veith $M$, Tüffers J, Peychev $E$, et al. The distribution of alpha- 1 antitrypsin genotypes between patients with COPD/ emphysema, asthma and bronchiectasis. Int I Chron obstruct Pulmon Dis. 2020;15:2827-36.

19. Parr DG, Guest PG, Reynolds JH, et al. Prevalence and impact of bronchiectasis in alpha1-antitrypsin deficiency. Am J Respir Crit
Care Med 2007:176:1215-21

20. Yamashiro T, Matsuoka S, Estépar RSJ, et al. Quantitative airway assessment on computed tomography in patients with alpha1antitrypsin deficiency. COPD. 2009;6:468-77.

21. Cazzola M, Stolz D, Rogliani P, Matera MG. Alpha1-Antitrypsin deficiency and chronic respiratory disorders. Eur Respir Rev. 2020;29:190073

22. Weinmann $\mathrm{GG}$, Chiang YP, Sheingold $\mathrm{S}$. The national emphysema treatment trial (NETT): a study in agency collaboration. Proc Am Thorac Soc. 2008:5:381-4.

23. Gulack BC, Mulvihill MS, Ganapathi AM, et al. Survival after lung transplantation in recipients with alpha-1-antitrypsin deficiency compared to other forms of chronic obstructive pulmonary disease: a national cohort study. Transpl Int. 2018;31:45-55.

24. Crystal RG. Alpha 1-antitrypsin deficiency, emphysema, and liver disease. Genetic basis and strategies for therapy. J Clin liver disease. Genetic basis a
Invest. 1990;85:1343-52.

25. Wewers MD, Casolaro MA, Sellers $S E$, et al. Replacement therapy for alpha 1-antitrypsin deficiency associated with emphysema. N Eng/ J Med. 1987;316:1055-62.

26. Barker AF, Iwata-Morgan I, Oveson L, Roussel R. Pharmacokinetic study of alpha1-antitrypsin infusion in alpha1antitrypsin deficiency. Chest. 1997;112:607-13.

27. Sandhaus RA, Turino G, Brantly ML, et al. The diagnosis and management of alpha- 1 antitrypsin deficiency in the adult. Chronic Obstr Pulm Dis. 2016;3:668-82.

28. Tortorici MA, Rogers JA, Vit O, et al. Quantitative disease progression model of alpha-1 proteinase inhibitor therapy on computed tomography lung density in patients with alpha-1 antitrypsin deficiency. Br I Clin Pharmacol. 2017;83:2386-97. 
29. Campos MA, Kueppers F, Stocks JM, et al. Safety and pharmacokinetics of $120 \mathrm{mg} / \mathrm{kg}$ versus $60 \mathrm{mg} / \mathrm{kg}$ weekly intravenous infusions of alpha- 1 proteinase inhibitor in alpha- 1 antitrypsin deficiency: a multicenter, randomized, double-blind, antitrypsin deficiency: a multicenter, randomized,
crossover study (SPARK). COPD. 2013;10:687-95.

30. Sorrells $S$, Camprubi S, Griffin R, et al. SPARTA clinical trial design: exploring the efficacy and safety of two dose regimens of alpha1-proteinase inhibitor augmentation therapy in alpha1antitrypsin deficiency. Respir Med. 2015;109:490-9.

31. Barjaktarevic I, Miravitlles M. Alpha-1 antitrypsin (AAT) augmentation therapy in individuals with the $\mathrm{PI}{ }^{*} \mathrm{MZ}$ genotype: a pro/con debate on a working hypothesis. BMC Pulm Med. 2021;21:99.

32. Balbi B, Ferrarotti I, Miravitlles M. Efficacy of augmentation therapy for emphysema associated with alpha1-antitrypsin deficiency: enough is enough. Eur Respir J. 2016;47:35-8.

33. Dirksen A, Dijkman JH, Madsen F, et al. A randomized clinical trial of alpha(1)-antitrypsin augmentation therapy. Am J Respir Crit Care Med. 1999;160:1468-72.

34. Dirksen A, Piitulainen E, Parr DG, et al. Exploring the role of CT densitometry: a randomised study of augmentation therapy in alpha1-antitrypsin deficiency. Eur Respir J. 2009:33:1345-53.

35. Chapman KR, Burdon JGW, Piitulainen E, et al. Intravenous augmentation treatment and lung density in severe $\alpha .1$ antitrypsin deficiency (RAPID): a randomised, double-blind, placebo-controlled trial. Lancet. 2015;386:360-8.

36. MCElvaney NG, Burdon J, Holmes M, et al. Long-term efficacy and safety of $\alpha 1$ proteinase inhibitor treatment for emphysen caused by severe $\alpha 1$ antitrypsin deficiency: an open-label extension trial (RAPID-OLE). Lancet Resp Med. 2017:5:51-60.

37. Rahaghi FF, Miravitlles M. Long-term clinical outcomes following treatment with alpha 1-proteinase inhibitor for COPD associated with alpha- 1 antitrypsin deficiency: a look at the evidence. Respir Res. 2017:18:105.

38. Rahaghi FF, Monk R, Ramakrishnan V, et al. Alpha-1 antitrypsin augmentation therapy improves survival in severely deficient patients with predicted FEV1 between $10 \%$ and $60 \%$ : a retrospective analysis of the NHLBI alpha- 1 antitrypsin deficiency registry. Int I Chron Obstruct Pulmon Dis. 2020;15:3193-9.

39. Banga A, Gildea T, Rajeswaran J, et al. The natural history of lung function after lung transplantation for alpha(1)-antitrypsin deficiency. Am J Respir Crit Care Med. 2014;190:274-81.

40. Boerema DJ, An B, Gandhi RP, et al. Biochemical comparison of four commercially available human alpha1-proteinase inhibitors for treatment of alpha1-antitrypsin deficiency. Biologicals. 2017:50:63-72.

41. Arora V, Cruz M, Lang J, et al. Comparison of the liquid and Iyophilized formulations of Prolastin(R)-C for alpha1-antitrypsin deficiency: biochemical characteristics, pharmacokinetics, safety and neoantigenicity in rabbits. Biologicals. 2019;62:77-84.

42. Barker AF, Campos MA, Brantly ML, et al. Bioequivalence of a liquid formulation of alpha1-proteinase inhibitor compared with prolastin(R)-C (Lyophilized Alpha1-PI) in alpha1-antitrypsin deficiency. COPD. 2017:14:590-6.

43. Sieluk J, Levy J, Sandhaus RA, et al. Costs of medical care among augmentation therapy users and non-users with alpha-1 antitrypsin deficiency in the United States. Chronic Obstr Pulm Dis. 2018;6:6-16.

44. Chorostowska-Wynimko J, Barrecheguren M, Ferrarotti I, et al. New patient-centric approaches to the management of alpha-1 antitrypsin deficiency. Int I Chron Obstruct Pulmon Dis. 2020;15:345-355.

45. Campos MA, Runken MC, Davis AM, et al. Impact of a health management program on healthcare outcomes among patients on augmentation therapy for alpha 1-antitrypsin deficiency: an on augmentation therapy for alpha 1-antitrypsin defcien
insurance claims analysis. Adv Ther. 2018:35:467-81.

46. Annunziata A, Lanza M, Coppola A, et al. Alpha-1 antitrypsin deficiency: home therapy. Front Pharmacol. 2021:12:575402.

47. ClinicalTrials.gov. Phase 1 Study to Assess the Safety, PK and PD of INBRX-101 in Adults With Alpha-1 Antitrypsin Deficiency (rhAAT-Fc). ClinicalTrails.gov Identifier: NCT03815396. Available at: https://clinicaltrials.gov/ct2/show/NCT03815396 (accessed

\section{November 2021)}

48. MCNulty MU, Silberstein DZ Kuhn BT, et al. Alpha-1 antitrypsin deficiency and recombinant protein sources with focus on plant sources: updates, challenges and perspectives. Free Radic Biol Med. 2021:163:10-30.

49. Bari E, Ferrarotti I, Di Silvestre D, et al. Adipose mesenchymal extracellular vesicles as alpha-1-antitrypsin physiological delivery systems for lung regeneration. Cells. 2019;8:965.

50. Ni K, Mian MUM, Meador C, et al. Oncostatin M and TNF-alpha induce alpha-1 antitrypsin production in undifferentiated adipose stromal cells. Stem Cells Dev. 2017;26:1468-76.

51. Hubbard RC, Brantly ML, Sellers SE, et al. Anti-neutrophielastase defenses of the lower respiratory tract in alpha 1-antitrypsin deficiency directly augmented with an aerosol of alpha 1-antitrypsin. Ann Intern Med. 1989;111:206-12.

52. Hubbard RC, MCElvaney NG, Sellers SE, et al. Recombinant DNA-produced alpha 1-antitrypsin administered by aeroso augments lower respiratory tract antineutrophil elastase defenses in individuals with alpha 1-antitrypsin deficiency. J Clin defenses in individuals with

53. Usmani OS. Feasibility of aerosolized alpha-1 antitrypsin as a therapeutic option. Chronic Obstr Pulm Dis. 2020;7:272-9.

54. Monk R, Graves M, Williams P, Strange C. Inhaled alpha 1-antitrypsin: gauging patient interest in a new treatment. COPD. 2013;10:411-5.

55. Stolk J, Tov N, Chapman KR, et al. Efficacy and safety of inhaled alpha1-antitrypsin in patients with severe alpha1-antitrypsin deficiency and frequent exacerbations of COPD. Eur Respir 2019;54:1900673

56. ClinicalTrials.gov. International Study Evaluating the Safety and Efficacy of Inhaled, Human, Alpha-1 Antitrypsin (AAT) in Alpha-1 Antitrypsin Deficient Patients With Emphysema. ClinicalTrials Identifier: NCT01217671. Available at: https://clinicaltrials.gov/ ct2/show/NCT01217671 (accessed 3 November 2021).

57. ClinicalTrials.gov. Phase II, Safety and Efficacy Study of Kamadaalpha-1-antitrypsin (AAT) for Inhalation. ClinicalTrials.gov Identifier: NCT02001688. Available at: https://clinicaltrials gov/ ct2/show/NCT02001688 (accessed 3 November 2021).

58. ClinicalTrials.gov. Safety Study of an Aerosolized, Recombinan Alpha 1-Antitrypsin in Subjects With Alpha 1-Antitrypsin Deficiency. ClinicalTrials.gov Identifier: NCT00161707. Available at: https://clinicaltrials.gov/ct2/show/NCT00161707 (accessed 3 November 2021)

59. ClinicalTrials.gov. Efficacy and Safety of Alpha1-Proteinase Inhibitor (Human), Modified Process (Alpha-1 MP) in Subjects With Pulmonary Emphysema Due to Alpha1 Antitrypsin Deficiency (AATD) (SPARTA). ClinicalTrials.gov Identifier. NCT01983241. Available at: https://www.clinicaltrials.gov/ct2/ show/NCT01983241 (accessed 3 November 2021).

60. Griese M, Scheuch G. Delivery of alpha-1 antitrypsin to airways. Ann Am Thorac Soc. 2016;13 Suppl.4:S346-51.

61. Cantor JO, Shteyngart B, Cerreta JM, et al. The effect of hyaluronan on elastic fiber injury in vitro and elastaseinduced airspace enlargement in vivo. Proc SOc Exp Biol Med. 2000;225:65-71.

62. Cantor J, Armand G, Turino G. Lung hyaluronan levels are decreased in alpha- 1 antiprotease deficiency COPD. Respir Med. 2015;109:656-9.

63. Cantor J, Ma S, Turino G. A pilot clinical trial to determine the safety and efficacy of aerosolized hyaluronan as a treatment for COPD. Int I Chron Obstruct Pulmon Dis. 2017:12:2747-52.

64. Cantor J, Ma S, Liu X, et al. A 28-day clinical trial of aerosolized hyaluronan in alpha-1 antiprotease deficiency COPD using desmosine as a surrogate marker for drug efficacy. Respir Med. 2021;182:106402

65. Stockley R, De Soyza A, Gunawardena K, et al. Phase II study of a neutrophil elastase inhibitor (AZD9668) in patients with bronchiectasis. Respir Med. 2013:107:524-33.

66. ClinicalTrials.gov. A 12-week Study Treating Participants Who Have alpha1-antitrypsin-related COPD With Alvelestat (MPH966) or Placebo. (ASTRAEUS). ClinicalTrials.gov Identifier. NCT03636347. Available at: https://clinicaltrials.gov/ct2/show NCT03636347 (accessed 3 November 2021).
67. ClinicalTrials.gov. Alvelestat (MPH966) for the Treatment of ALpha-1 ANTitrypsin Deficiency (ATALANTa). ClinicalTrials.gov
Identifier: NCT03679598. Available at: https://clinicaltrials.gov/ ct2/show/NCT03679598 (accessed 3 November 2021).

68. ClinicalTrials.gov. Evaluation of the Efficacy and Safety of VX-864 in Subjects With the Pizz Genotype. ClinicalTrials.gov Identifier NCT04474197. Available at: https://clinicaltrials.gov/ct2/show/ NCT04474197 (accessed 3 November 2021).

69. Vertex. VX-864 Phase 2 Results and Alpha-1-Antitrypsin Deficiency (AATD) Program Update. 2021. Available at: https:// investors.vrtx.com/events/event-details/vx-864-phase-2results-and-alpha-1-antitrypsin-deficiency-aatd-programupdate (accessed 30 November 2021)

70. Strnad P, Turner AM, Trautwein C, et al. ARO-AAT reduces serum and intra-hepatic Z-AAT in PiZZ AATD patients with liver disease leading to improvements in clinically relevant liver biomarkers Annual Meeting of the American Association for the Study of Liver Disease (AASID), $2020.1 P 14$

71. Carey EJ, Iyer VN, Nelson DR, et al. Outcomes for recipients of liver transplantation for alpha-1-antitrypsin deficiency-related cirrhosis. Liver Transpl. 2013;19:1370-6.

72. Clark VC. Liver transplantation in alpha-1 antitrypsin deficiency. Clin Liver Dis. 2017;21:355-65.

73. Bañuls L, Pellicer D, Castillo S, et al. Gene therapy in rare respiratory diseases: what have we learned so far? J Clin Med. 2020;9:2577.

74. Brantly ML, Spencer LT, Humphries M, et al. Phase I trial of intramuscular injection of a recombinant adeno-associated virus serotype 2 alphal-antitrypsin (AAT) vector in AAT-deficient adults. Hum Gene Ther. 2006;17:1177-86.

75. Flotte TR, Trapnell BC, Humphries M, et al. Phase 2 clinical trial of a recombinant adeno-associated viral vector expressing alpha1-antitrypsin: interim results. Hum Gene Ther. 2011;22:1239-47.

76. De B. Heguy A Leopold PL et al Intrapleural administration of a serotype 5 adeno-associated virus coding for alpha1antitrypsin mediates persistent, high lung and serum levels of alpha1-antitrypsin. Mol Ther. 2004;10:1003-10.

77. De BP, Heguy A, Hackett NR, et al. High levels of persistent expression of alpha1-antitrypsin mediated by the nonhuman primate serotype rh.10 adeno-associated virus despite preexisting immunity to common human adeno-associated viruses. Mol Ther. 2006;13:67-76

78. Stiles KM, Sondhi D, Kaminsky SM, et al. Intrapleural gene therapy for alpha-1 antitrypsin deficiency-related lung disease. Chronic Obstr Pulm Dis. 2018;5:244-257.

79. Chiuchiolo MJ, Kaminsky SM, Sondhi D, et al. Phase I/II study of intrapleural administration of a serotype rh.10 replicationdeficient adeno-associated virus gene transfer vector expressing the human alpha1-antitrypsin CDNA to individuals with alpha1-antitrypsin deficiency. Hum Gene Ther Clin Dev. 2014:25:112-33.

80. ClinicalTrials.gov. Safety Dose Finding Study of ADVM-043 Gene Therapy to Treat Alpha-1 Antitrypsin (A1AT) Deficiency (ADVANCE). ClinicalTrials.gov Identifier: NCT02168686. Available at: https://clinicaltrials.gov/ct2/show/NCT02168686 (accessed 3 November 2021)

81. Adverum. Adverum Biotechnologies Provides Program Updates. 2018. Available at: https://investors.adverum.com/ news/news-details/2018/Adverum-Biotechnologies-ProvidesProgram-Updates-2018-11-1-2018-11-1/default.aspx (accessed 3 November 2021)

82. Rahaghi FF, Miravitlles M. Long-term clinical outcomes following treatment with alpha 1-proteinase inhibitor for COPD associated with alpha-1 antitrypsin deficiency: a look at the evidence. Respir Res. 2017;18:105

83. Rahaghi FF, Monk R, Ramakrishnan V, et al. Alpha-1 antitrypsin augmentation therapy improves survival in severely deficient patients with predicted FEV1 between $10 \%$ and $60 \%$ : a retrospective analysis of the NHLBI alpha-1 antitryps deficiency registry. Int I Chron Obstruct Pulmon Dis. 2020;15:3193-9. 